\title{
Fresh air dehumidification in a novel liquid desiccant-air contacting device
}

\author{
J. R. Mehta ${ }^{1}$, H. C. Badrakia ${ }^{2}$ \\ '(Mechanical Engineering Department, The M S University of Baroda, India) \\ ${ }^{2}$ (Mechanical Engineering Department, Noble Engineering College, India)
}

\begin{abstract}
Craving for higher comfort and rise in living standards in various societies have led to higher demand for air conditioning. Energy consumption is related with climate change. Desiccant based air dehumidification systems can run with waste heat or renewable source of energy. Liquid desiccant (LD) based air conditioning systems are many times conceived as complicated and costly. A novel but simple internally cooled LDAD system is developed, integrated and tested in this work. Outdoor air was passed through the coil, thus making it essentially a study of fresh air enthalpy removal. Temperature range of 14 to $22^{\circ} \mathrm{C}$ was used for cooling water, which can be catered by a single stage vapour absorption refrigeration system on lower side or cooling tower on the higher side. The cooling capacity of the system increased up to 54\%, compared to conventional chilled water coil. Latent heat fraction removed was also higher, showing usefulness of the system for higher latent load applications. Higher air velocity was found to give higher cooling capacity, while moisture removal per $\mathrm{kg}$ of air and effectiveness were higher at lower air velocities.
\end{abstract}

Keywords: Air Conditioning, Contacting Device, Dehumidification, Energy, Liquid Desiccant

\section{Introduction}

Growth of economy is related with higher energy consumption and consequent pollution concerns. It would be preferable to use renewable energy source or waste heat source for providing air conditioning. Liquid desiccant (LD) based air conditioning or air dehumidification (LDAD) systems can run on these sources of energy [1-3]. They have additional advantages like energy storage and environmently benign working substance [4]. These systems are many times conceived as complicated and consuming higher parasitic power [5]. Internally cooled LDAD helps reducing parasitic power by reducing flow rate of LD as liquid flow rate can be reduced by widening concentration range in dehumidifier [6]. Liquid desiccant and air are brought in contact in a device called 'contacting device' for required heat and mass transfer. Out of various contacting devices like spray tower, packed bed and falling film, falling film type has lower pressure drop across it [7]. Rotating disk type contacting device would also be preferable for lower pressure drop [8]. Mehta and Sujela simulated various configurations of rotating disk type contacting device [9]. A LD based air conditioning system with internally cooled falling film type dehumidifier was tested by Jones and Harrison [10]. Cooling COP of 0.48 is reported but electrical power consumption was as high as $1.31 \mathrm{~kW} / \mathrm{TR}$. A novel contacting device is developed in this work, which is simpler as it is fabricated by integrating liquid desiccant pumping and distribution system with a conventional cooling coil used in air conditioning applications. The effectiveness and capacity enhancement in terms of total heat and latent heat delivered is investigated and reported in this paper.

\section{Experimental Set-Up and Instrumentation}

The experimental set up consists of an internally cooled liquid desiccant-air contacting device, LD tanks, LD pump and tubings, LD distribution and collection system and a blower. The internally cooled contacting device consists of a four row finned tube flooded water type coil. There are 17 tubes with internal diameter of $8.8 \mathrm{~mm}$, arranged in serpentine fashion in each row and all four rows are in series. Rows are arranged in staggered fashion with transverse as well as diagonal tube pitch equal to $25 \mathrm{~mm}$. Fins are $0.2 \mathrm{~mm}$ thick, wave height is $1 \mathrm{~mm}$, wave projected length is $4 \mathrm{~mm}$ and fin density is 12 FPI.

An LD distribution system is designed using multiple plastic tubes with fine holes in parallel (Fig. 1). A diaphragm pump is used for pumping LD from supply tank. There is provision for recirculation to reduce pumping rate as required. The $\mathrm{LD}$ fall in form of droplets, through holes in the tube over fins or tubes and then slide down. It is collected in a tray at bottom and drained into return tank. A centrifugal blower with $200 \mathrm{~mm}$ diameter and $100 \mathrm{~mm}$ width is used for pushing the air through the coil. The speed of the blower can be varied by changing the supply voltage, which will change air volume flow rate and velocity through the coil. Specification of various instruments used in experiments is given in Table 1. 


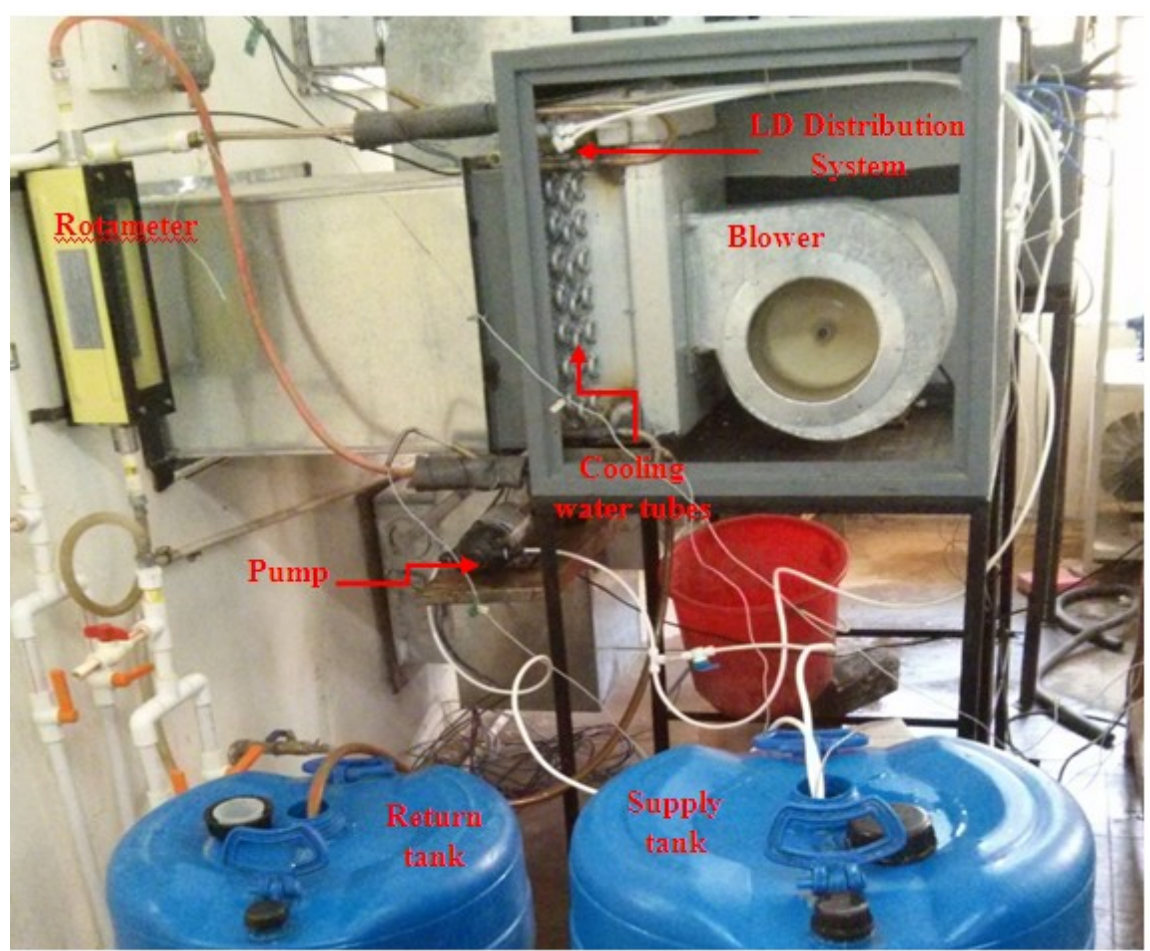

Figure 1: Experimental set-up

Table 1: Specifications of Instruments Used in Experiments

\begin{tabular}{|c|c|c|c|c|c|}
\hline $\begin{array}{c}\text { Sr. } \\
\text { No. }\end{array}$ & $\begin{array}{c}\text { Property } \\
\text { measured }\end{array}$ & Name of Instruments & Measuring Range & Accuracy & Resolution \\
\hline 1 & $\begin{array}{c}\text { Water \& LD } \\
\text { Temperatures }\end{array}$ & $\begin{array}{c}\text { ADI Temperature Scanner } \\
\text { DTS3508 (RTD PT-100) }\end{array}$ & $-100{ }^{\circ} \mathrm{C}$ to $200{ }^{\circ} \mathrm{C}$ & $\pm 0.1 \%$ & $0.1{ }^{\circ} \mathrm{C}$ \\
\hline 2 & LD Sp. Gravity & Hydrometer & 1 to 1.5 & 0.005 & 0.005 \\
\hline 3 & Air Velocity & $\begin{array}{c}\text { Testo make Vane probe, } \\
\varnothing 100 \mathrm{~mm}\end{array}$ & $\begin{array}{c}+0.1 \text { to }+15 \mathrm{~m} / \mathrm{s} \\
0 \text { to }+60^{\circ} \mathrm{C}\end{array}$ & $\begin{array}{c} \pm(0.1 \mathrm{~m} / \mathrm{s}+1.5 \% \text { of } \mathrm{m} . \mathrm{v} .) \\
\pm 0.5{ }^{\circ} \mathrm{C}\end{array}$ & 0.01 \\
\hline 4 & $\begin{array}{c}\text { Air Temperature } \\
\text { and Relative } \\
\text { Humidity }\end{array}$ & $\begin{array}{c}\text { Testo make Humidity and } \\
\text { temperature probe }\end{array}$ & $\begin{array}{c}0 \text { to } 100 \% \mathrm{RH} \\
-20 \text { to }+70^{\circ} \mathrm{C}\end{array}$ & $\begin{array}{c} \pm(1.0 \% \mathrm{RH}+0.7 \% \text { of } \\
\text { m.v. }) 0 \text { to } 90 \% \mathrm{RH}\end{array}$ & 0.1 \\
\hline
\end{tabular}

Vane probe and humidity and temperature probe can be connected to a datalogger, which can transfer the data to a PC and it can be stored. Mass flow rate of solution was measured by dividing change in mass of supply tank by the steady state period time duration. Water flow rate was measured with a rotameter, range 0 to $2000 \mathrm{~kg} / \mathrm{h}$ and resolution equal to $25 \mathrm{~kg} / \mathrm{h}$.

\section{Experimentation}

Aqueous calcium chloride solution was used as liquid desiccant because of its lower cost and easy availability. $41 \%$ concentration was used in all experiments based on crystallization consideration. LD flow rate was $55 \mathrm{~kg} / \mathrm{h}$ in all experiments, the highest flow rate achievable with small diaphragm pump with $14 \mathrm{~W}$ rating. Experiments were performed first without LD, i.e. using only cooling water passed through coil with water temperature of 14,18 and $22^{\circ} \mathrm{C}$. Flow rate of water was set at maximum possible value, $800 \mathrm{~kg} / \mathrm{h}$ for least temperature drop across coil. Immediately after the water only experiment, experiment using LD along with cooling water were performed using LD over the surface of the chilled water coil.

Experiments were performed in the month of June, when the ambient humidity is quite high. Comparatively low, moderate and high humidities were observed in afternoon, morning and evening respectively. Fan was run at three different speeds, giving three different L/G (liquid to gas flow rate) ratios for each temperature of supply water. In each experiment, system was run till steady state was achieved and then readings were averaged over a few minutes of steady state run of the system. The performance parameters like change in humidity ratio $(\Delta \mathrm{W})$, humidity effectiveness $\left(\varepsilon_{\mathrm{h}}\right)$, sensible cooling rate and total cooling rate were calculated. Humidity effectiveness was found on the basis of cooling water temperature at inlet of the coil 
rather than LD inlet temperature, considering the temperature difference between them as limitation of the contacting device.
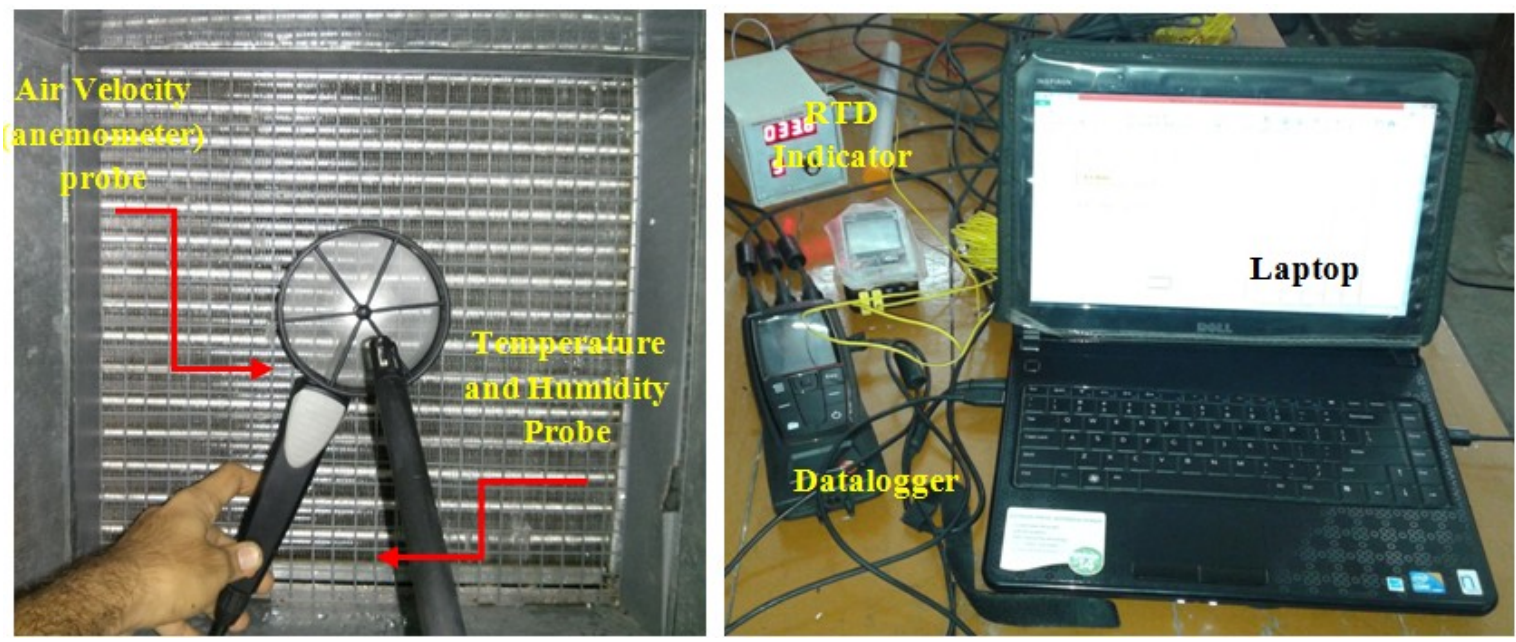

Figure 2: Instrumentation and datalogging system

\section{Results and Discussion}

Table 1 presents comparison of performance of the coil used only with cooling water and that with LD in contact with air, cooled by water. The two parts of the table (left and right) show results for two different water temperatures. Inlet air humidity ratio and air velocity were same in both experiments.

It is seen that moisture removal rate increases significantly when LD solution is used, moisture removal rate increases by $37.2 \%$ for cooling water temperature of $18^{\circ} \mathrm{C}$. Though total cooling rate increases marginally, latent cooling rate increases significantly. At $22^{\circ} \mathrm{C}$, the rise in moisture removal rate as well as latent heat factor is much higher. Thus, using LD helps to remove latent load more effectively, more so at higher water temperatures, when the dew point temperature of air could be very near to cooling water temperature.

The same coil provided around 32\% higher capacity when LD system was integrated with the conventional coil at $22^{\circ} \mathrm{C}$ water temperature. The decrease in enthalpy and moisture effectiveness is due to lower water vapour pressure exerted by LD at given inlet water temperature. This shows that there is still much more potential for heat as well as removal if LD is cooled more effectively by the cooling water.

Table 2: Effect of LD on Performance of the System

\begin{tabular}{|c|c|c|c|c|c|c|c|}
\hline \multirow[b]{2}{*}{ Parameter } & \multirow[b]{2}{*}{ Unit } & \multicolumn{2}{|c|}{$\begin{array}{c}\mathrm{T}_{\mathrm{w}}=18^{\circ} \mathrm{C}, \mathrm{W}_{\mathrm{i}}=20.3 \mathrm{~g} / \mathrm{kg}_{\mathrm{da}} \\
\mathrm{V}_{\mathrm{a}}=1.28 \mathrm{~m} / \mathrm{s}\end{array}$} & \multirow[b]{2}{*}{$\%$ rise } & \multicolumn{2}{|c|}{$\begin{array}{c}\mathrm{T}_{\mathrm{w}}=22^{\circ} \mathrm{C}, \mathrm{W}_{\mathrm{i}}=20.3 \mathrm{~g} / \mathrm{kg}_{\mathrm{da}} \\
\mathrm{V}_{\mathrm{a}}=1.28 \mathrm{~m} / \mathrm{s}\end{array}$} & \multirow[b]{2}{*}{$\%$ rise } \\
\hline & & Water & Water + LD & & Water & Water + LD & \\
\hline$\Delta \mathbf{W}_{\mathrm{a}}$ & $\mathrm{g} / \mathrm{kg}_{\mathrm{da}}$ & 4.30 & 5.90 & 37.2 & 2.90 & 5.4 & 86.2 \\
\hline MRR & $\mathrm{kg} / \mathrm{h}$ & 3.69 & 5.06 & 37.2 & 2.49 & 4.63 & 86.2 \\
\hline $\mathbf{Q}_{\mathrm{s}}$ & $\mathrm{kW}$ & 3.313 & 2.74 & -17.4 & 2.50 & 2.33 & -6.7 \\
\hline $\mathbf{Q}_{\mathrm{I}}$ & $\mathrm{kW}$ & 2.695 & 3.68 & 36.4 & 1.84 & 3.39 & 84.2 \\
\hline $\mathbf{Q}_{\mathrm{t}}$ & $\mathrm{kW}$ & 6.007 & 6.41 & 6.8 & 4.34 & 5.72 & 31.9 \\
\hline $\boldsymbol{\varepsilon}_{\gamma}$ & & 0.607 & 0.38 & -37.1 & 0.67 & 0.39 & -43.9 \\
\hline$\varepsilon_{h}$ & & 0.67 & 0.46 & -31.5 & 0.69 & 0.47 & -32.4 \\
\hline LHF & & 0.449 & 0.57 & 27.6 & 0.43 & 0.59 & 39.5 \\
\hline
\end{tabular}

Table 3 shows the effect of inlet humidity ratio on performance of LDAD (left part). The right part of the table shows the effect of air velocity on performance of the system. 
Table 3: Effect of Humidity Ratio and Air Velocity on Performance of LDAD

\begin{tabular}{|c|c|c|c|c|c|c|c|}
\hline & & $\begin{array}{c}V_{a}=1.28 \mathrm{~m} / \mathrm{s} \\
t_{w}=14^{\circ} \mathrm{C}\end{array}$ & $\begin{array}{c}V_{a}=1.28 \mathrm{~m} / \mathrm{s} \\
t_{w}=14^{\circ} \mathrm{C}\end{array}$ & $\begin{array}{c}W_{i}=23.6 \mathrm{~kg} / \mathrm{kg} d a \\
t_{w}=18^{\circ} \mathrm{C}\end{array}$ & $\begin{array}{c}W_{i}=23.7 \mathrm{~kg} / \mathrm{kg} d a \\
t_{w}=18^{\circ} \mathrm{C}\end{array}$ & \\
\hline Parameter & $\mathbf{U n i t}$ & $\begin{array}{c}W_{i}=16.8 \\
\mathrm{~kg} / \mathrm{kg}_{d a}\end{array}$ & $\begin{array}{c}W_{i}=19.4 \\
\mathrm{~kg} / \mathrm{kg}_{d a}\end{array}$ & $\% \mathrm{rise}$ & $V_{a}=1.28 \mathrm{~m} / \mathrm{s}$ & $V_{a}=0.85 \mathrm{~m} / \mathrm{s}$ & $\% \mathrm{rise}$ \\
\hline $\mathbf{A W}_{\mathbf{a}}$ & $\mathrm{g} / \mathrm{kg}_{\mathrm{da}}$ & 4.40 & 6.70 & 52.3 & 8.40 & 9.20 & 9.5 \\
\hline $\mathbf{M R R}$ & $\mathrm{kg} / \mathrm{h}$ & 3.78 & 5.75 & 52.3 & 7.21 & 5.24 & -27.3 \\
\hline $\mathbf{Q}_{\mathbf{s}}$ & $\mathrm{kW}$ & 3.62 & 3.12 & -13.9 & 2.14 & 1.61 & -24.6 \\
\hline $\mathbf{Q}_{\mathbf{l}}$ & $\mathrm{kW}$ & 2.81 & 4.13 & 46.7 & 5.21 & 3.77 & -27.5 \\
\hline $\mathbf{Q}_{\mathbf{t}}$ & $\mathrm{kW}$ & 6.44 & 7.25 & 12.6 & 7.34 & 5.38 & -26.7 \\
\hline $\boldsymbol{\varepsilon}_{\boldsymbol{\gamma}}$ & & 0.34 & 0.43 & 26.9 & 0.45 & 0.49 & 8.9 \\
\hline $\boldsymbol{\varepsilon}_{\mathbf{h}}$ & & 0.48 & 0.50 & 4.8 & 0.48 & 0.53 & 9.8 \\
\hline $\mathbf{L H F}$ & & 0.44 & 0.57 & 30.2 & 0.71 & 0.70 & -1.1 \\
\hline
\end{tabular}

It is seen that when humidity ratio increases from 16.8 to $19.4 \mathrm{~kg} / \mathrm{kg}_{\mathrm{da}}$ (increase by $15.5 \%$ ), the moisture removal rate (MRR) increases by $52.3 \%$. Thus, the performance of the system is very sensitive to inlet air humidity ratio. Total cooling increased by $12.6 \%$, latent cooling increased by $46.7 \%$, while sensible cooling reduced by $13.9 \%$ when humidity ratio of inlet air increased. When the moisture removal rate increases, latent heat generation increases and cooling provided by water is not very effective.

It is seen that when air velocity is reduced from 1.28 to $0.85 \mathrm{~m} / \mathrm{s}$ (reduction by $33.6 \%$ ), change in humidity ratio of air increases from 8.4 to $9.2 \mathrm{~kg} / \mathrm{kg}_{\mathrm{da}}$. MRR reduced by $27.3 \%$ due to reduced air flow rate. Thus, if lower dew point of supply air is required, air velocity may be reduced, but that will lead to reduction in capacity of the system for a given coil. Moisture and humidity effectiveness of the system rises but LHF changes marginally when air velocity is reduced.

\section{Conclusion}

A simple and easy to implement internally cooled LDAD system is integrated and demonstrated in this paper. The additional power consumption for LDAD system as compared to only water cooled system was 14 W for LD pump. With such small power addition, capacity of the cooling coil could be increased by around $32 \%$ at $22^{\circ} \mathrm{C}$ cooling water temperature and $41 \%$ aqueous calcium chloride as LD. Even at $18^{\circ} \mathrm{C}$, though total cooling rate increased by around $6 \%$, latent cooling increased by around $36 \%$, showing the usefulness of the system for high latent loads. The performance of the system is very sensitive to inlet air humidity, more the humidity, better the performance. Lowering the velocity marginally improves moisture and enthalpy effectiveness but reduces the capacity of the coil significantly. The performance of the system can be further improved by more uniform wetting of the coil.

\section{References}

[1] J. R. Mehta, and M. V. Rane, Liquid desiccant based solar air conditioning sysem with novel evacuated tube collector as regenerator, Procedia Engineering, 51, 2013, 688 - 693 .

[2] J. R. Mehta, and S. M. Gandhi, Investigation of solar still as liquid desiccant regenerator, Proc. 4th Nirma University International Conference on Engineering (NUiCONE), 2013, paper id 2285.

[3] S. N. Vanjara, Investigation of liquid desiccant regeneration using solar energy or waste heat, M. E. diss., The M. S. University of Baroda, Vadodara, India, 2014

[4] W. Kessling, E. Laevemann, and M. Peltzer, Energy storage in open cycle liquid desiccant cooling systems, Int J. Refrig., 21(2), $1998,150-156$.

[5] K. Gommed, and G. Grossman, Experimental investigation of liquid desiccant system for solar cooling and dehumidification, Solar Energy, 81, 2007, 131-138.

[6] A. Lowenstein, S. Slayzak and E. Kozubal, A zero carryover liquid desiccant air conditioner for solar applications, Proc. ASME International Solar Energy Conference (ISEC), 2006. paper id 99079.

[7] S. Jain, and P. K. Bansal, Performance analysis of liquid desiccant dehumidification systems, Int J. Refrig.,30, 2007, 861-872.

[8] M. V. Rane, S. V. Kota Reddy, and R. R. Easow, Energy efficient liquid desiccant-based dryer, Applied Thermal Engineering, 25, 2005, 769-981.

[9] J. R. Mehta, and A. A. Sujela, Conditioning of outdoor air using rotating disk type liquid desiccant-air contacting device, IOSR Journal of Mechanical and Civil Engineering (ICAET-2014), 41-45.

[10] B. M. Jones, and S. J. Harrison, First results of a solar-thermal liquid desiccant air conditioning concept, $1^{\text {st }}$ International Congress on Heating, Cooling and Buildings, Lisbon-Portugal, paper id-480. 